\title{
Method Development for Detection of E545A Mutation PIK3CA Gene in Breast Cancer Patients Using Tm Shift SYBR Green I qPCR
}

\author{
Fuad Al Ahwani ${ }^{1,}{ }^{*}$, Desriani $^{2}$, Utut Widyastuti ${ }^{1}$, Suharsono $^{1}$ \\ ${ }^{1}$ Department of Biotechnology Bogor Agricultural University, Jl. Raya Darmaga, Bogor, Indonesia \\ ${ }^{2}$ Research Center for Biotechnology, Indonesian Institute of Science, Jl. Raya Bogor No. 507, \\ Cibinong, Indonesia
}

\begin{abstract}
E545A is one of the point mutations, and its frequency is high in PIK3CA gene (3.8\%), particularly breast cancer patients in Singapore (13.8\%) and Mexico (11.5\%). In addition to induce breast cancer, the mutation also caused resistance of anti-HER2 in HER2 cancer subtype. The tremendous effect of this mutation was not supported by affordable detection method. This study aimed to develop a feasible and sensitive method for E545A detection. The developing method used Tm and $\mathrm{Ct}$ to identify samples. Based on optimization, the best condition was obtained with annealing temperature of $65^{\circ} \mathrm{C}$. At this condition, Tm and $\mathrm{Ct}$ of each sample were (a) exon $9\left(78.4^{\circ} \mathrm{C}\right.$ and $\left.13.005 \pm 0.007\right)$ and (b) E5454A $\left(80.4^{\circ} \mathrm{C}\right.$ and 10.07 \pm 0.1 . This method also demonstrated good precision as observed in coefficient variance of intra and inter assay (0). Thus, method for E5454A detection mutation was successfully developed.
\end{abstract}

Keywords: E545A, breast cancer, Ct, PIK3CA, precision, Tm

\section{Introduction}

Breast cancer is the most common cancer diagnosed in women. International Agency for Research on Cancer, WHO (2012), reported 1.67 million cases of breast cancer $(25 \%)$ and 522000 of cases led to the death $(14.7 \%)$. Mutation of proto-oncogene to oncogene could be one of factors primarily causing breast cancer. This mutation enhanced activity of proliferation, differentiation, and cell survival (Stare and Jozefowicz, 2008). Phosphatidylinositol-4,5-bisphosphate 3kinase, catalytic subunit alpha (PIK3CA) was mutated at $16-45 \%$ of breast cancer cases (Margone et al., 2012).

Mutation of PIK3CA was observed in all exons. It was reported that $87.5 \%$ of mutation was found at exon 9 (helical domain) and exon 20 (kinase domain) (Mihalcea et al., 2015). The E542 and E545 spots in helical domains and H1047 spot in kinase domains

\footnotetext{
*Corresponding author:

Fuad Al Ahwani

Department of Biotechnology Bogor Agricultural

University, Jl. Raya Darmaga, Bogor, Indonesia

E-mail: alahwanidauf@gmail.com
}

were found to have the highest mutation activity compared with other spots in PIK3CA in these three spots had a strong oncogenic activity, especially in $\mathrm{H} 1047$ spot. Bader et al., (2006) found that induction of E542, E545, and H1047 mutants in CAM (Chorioallantoic membrane) cells of chicken embryo could enhance angiogenesis activity of that cells. Oncogenicity of those three mutant spots was also demonstrated by other previous studies.

In addition to have high oncogenic activity, mutation of PIK3CA gene in HER-2 tumor subtype could also cause resistance of anti-HER2 in that tumor. Some anti-HER2 such as trastuzumab and lapatinib, that initially could be effective to that tumor, was no more ineffective as presence of PIK3CA gene mutation. Combination of anti-HER2 and PIK3CA seems to be a promising option to such condition (Rexer et al., 2014; Al-Sukhun et al., 2016).

Based on above description, PIK3CA gene mutation not only showed oncogenic activity, but also could affect drug resistance. Therefore, developing early detection method of PIK3CA gene is important, especially to determine the most appropriate treatment 
for breast cancer patients. Currently, commercial kit is only available for common detection mutation in PIK3CA gene such as E542K, E45K and H1047R, while detection method for E545A and other mutation spots are still limited. Operational cost of the available techniques is expensive, primarily due to the use of labeled probe, thus could not well be applied for large scale samples. The presence of affordable and sensitive technique is required primarily to attenuate operational cost and to enhance sample use in large scale. Lower operational cost is expected to reduce detection cost of breast cancer.

Therefore, as an initial step, this current work aimed to develop technique of mutant detection for PIK3CA gene E545A. The use of Tm shift SYBR green I qPCR is economically predicted to show better feasibility since its implementation only requires three unlabeled oligonucleotides and uses affordable dye of SYBR green I. The main principle of this method was to differentiate samples of cancer tissues through observation of Tm (melting temperature) and Ct (Cycle threshold) of resulting amplicons. Due to limitation of samples, the method development was carried out using recombinant plasmid of exon 9 and E545A.

\section{Materials and Methods}

\section{DNA template}

DNA insert was isolated from breast cancer tissue at M. Djamil Hospital, Padang. Recombinant plasmid at concentration of 3 ng was prepared using pGEM-T easy vector.

\section{Primer design}

Method of Tm shift SYBR green I qPCR used two forward primers and single reverse primer. Each forward primer used similar reverse primer, and designed to distinguish different targets. For this reason, each base at $3^{\prime}$ terminal forward primer had similar base to the target. Forward primer that could identify exon 9 had A base at 3' terminal, while forward primer that could identify E545A had C base at $3^{\prime}$ terminal. Addition of mismatch in the third base of $3^{\prime}$ terminal forward primer that could identify E545A was to enhance the specificity of the primer.

To differentiate amplification product, GC bases was added with different lengths in both forward primers. The bases was not complemented with genomic sequence. According to Wang et al., (2005), 14 GC was used in forward primer of E545A, and 6 GC for exon 9 (Table 1). This would resulted in different $\mathrm{Tm}$ and $\mathrm{Ct}$ for both amplicons. Primer that could identify E545A and exon 9 was called as long primer and short primer, respectively. The presence of the additional GC bases is potentially caused imbalanced GC base in 3' terminal from resulted amplicon. Thus, high GC bases was added in $5^{\prime}$ terminal of reverse primer (Table1), which was expected to balance GC distribution in amplicon and to increase the profile of formed peak.

\section{Optimization of Tm shift SYBR green I qPCR technique}

This optimization step consisted of two types: optimization 1 (low annealing temperature $\left(54.4-62^{\circ} \mathrm{C}\right)$, with extension phase and low concentration of long primer), and optimization 2 (high annealing temperature $\left(63-65^{\circ} \mathrm{C}\right)$, without extension phase and high concentration of long primer) as presented in Table 2. Optimization was carried out using CFX 96 thermal cycler, Biorad.

Amplification of optimization 1 involved 1 cycle pre-denaturation at $95^{\circ} \mathrm{C}$ for $3 \mathrm{~min}$; 34 cycles consisting of denaturation at $95^{\circ} \mathrm{C}$ for $10 \mathrm{sec}$, annealing at $54.4-62^{\circ} \mathrm{C}$ for $30 \mathrm{sec}$, and extension at $72^{\circ} \mathrm{C}$ for $3 \mathrm{~min}$. Amplification of optimization 2 involved 1 cycle pre-

Table 1. Primer used in the detection method using Tm shift SYBR green I qPCR.

\begin{tabular}{lll}
\hline Primer & Sequence & Amplicon \\
\hline FW_L & $5^{\prime}$-gcgggcagggcggctcctctctctgaaatcaccgc-3' & $\mathbf{8 9} \mathbf{~ b p}$ \\
FW_S & $5^{\prime}$-gcgggctcctctctctgaaatcactga-3' & $\mathbf{8 2 ~} \mathbf{~ p p}$ \\
R & $5^{\prime}$-gggccggatccattttagcacttacctgtg-3' & \\
\hline
\end{tabular}


denaturation at $95^{\circ} \mathrm{C}$ for $3 \mathrm{~min} ; 34$ cycles consisting of denaturation $95^{\circ} \mathrm{C}$ for $10 \mathrm{sec}$, annealing at $54.4-62^{\circ} \mathrm{C}$ for $30 \mathrm{sec}$. Melting curves of both optimizations were obtained by gradual enhancement of reaction temperature $\left(65-95^{\circ} \mathrm{C}\right)$ with ramping rate of $0.2^{\circ} \mathrm{C} / \mathrm{s}$. Reaction of qPCR was carried out in a single tube. Composition of qPCR consisted of $3 \mathrm{ng}$ DNA plasmid, 10 pmol primer fw (long and short) and reverse 10 pmol, $5 \mu \mathrm{L}$ Kapa SYBR fast master mix (2X) Universal, and $3.23 \mu \mathrm{L}$ nuclease free water.

Table 2. Technique optimization of Tm shift SYBR green I qPCR.

\begin{tabular}{cllll}
\hline Opt. & $\begin{array}{l}\text { Primer } \\
\text { Long } \\
(\mu \mathrm{M})\end{array}$ & $\begin{array}{l}\text { Primer } \\
\text { Short } \\
(\mu \mathrm{M})\end{array}$ & $\begin{array}{l}\text { Primer } \\
\text { Rev } \\
(\mu \mathrm{M})\end{array}$ & $\begin{array}{l}\text { Annealing } \\
\left({ }^{\circ} \mathrm{C}\right)\end{array}$ \\
\hline 1 & 0.0175 & 0.02 & 0.02 & 62 \\
\hline 2 & 0.03 & 0.0175 & 0.02 & $63-65$ \\
\hline
\end{tabular}

\section{Statistical Analysis}

Statistical analysis was performed using t-test or Mann-Whitney U to understand GC distribution in exon 9 and E545A amplicon. Prior to t-test, normality test was performed. If data were normally distributed, t-test was performed. Mann-Whitney $U$ test was performed if the data did not meet normal distribution. Coefficient Variance (CV) of intra-assay was determined to obtain precision of the developing technique.

\section{Results and Discussion}

\section{Normality test and t-test}

Prior to PCR reaction, it needs to know whether formed amplicon shows bimodal curve or not. Bimodal curve causes distractions of sample identification. Before conducting normality analysis and post hoc test, each sequence was divided into two groups; each consists of 10 bases. Additionally, the sequence was divided into two smaller groups (Table 3).
Table 3. GC content of exon 9 and E545A amplicon sequence.

\begin{tabular}{|c|c|c|c|}
\hline Amplicon & $\begin{array}{l}\text { Group } \\
\text { (bases) }\end{array}$ & $\begin{array}{l}\text { Sub Group } \\
\text { (bases) }\end{array}$ & $\begin{array}{c}\text { GC content } \\
(\%)\end{array}$ \\
\hline \multirow{8}{*}{ Exon 9} & \multirow{4}{*}{$\begin{array}{l}\text { Group I } \\
(1-50)\end{array}$} & $1-10$ & 80 \\
\hline & & $11-20$ & 40 \\
\hline & & $21-30$ & 70 \\
\hline & & $31-40$ & 40 \\
\hline & \multirow{4}{*}{$\begin{array}{l}\text { Group II } \\
(51-82)\end{array}$} & $41-50$ & 30 \\
\hline & & $51-60$ & 50 \\
\hline & & $61-70$ & 30 \\
\hline & & $71-82$ & 75 \\
\hline \multirow{9}{*}{ E545A } & \multirow{5}{*}{$\begin{array}{l}\text { Group I } \\
(1-50)\end{array}$} & $1-10$ & 90 \\
\hline & & $11-20$ & 70 \\
\hline & & $21-30$ & 40 \\
\hline & & $31-40$ & 80 \\
\hline & & $41-50$ & 20 \\
\hline & \multirow{4}{*}{$\begin{array}{l}\text { Group } 2 \\
(51-89)\end{array}$} & $51-60$ & 50 \\
\hline & & $61-70$ & 40 \\
\hline & & $71-80$ & 40 \\
\hline & & $81-89$ & 75 \\
\hline
\end{tabular}

Normality test Skewness and Kurtosis using SPSS software was carried out by comparing GC content in two sequence groups, exon 9 and E545A. The result demonstrated that data showed normal distribution since the values were in range of -1.96 and 1.96 (Table 4). Ghasemi and Zahediasl (2012) stated that Skewness and Kurtosis data were normally distributed when they were in that range. The data showed normal distribution, then t-test was performed.

Based on data evaluation using SPSS 16 at confidence interval of $95 \%$, $\mathrm{T}$ value of exon 9 and E545A was 7.213 and 7.187, respectively and df value of exon 9 and E545A was 7 and 8 , respectively. Using $\mathrm{T}$ table, $\mathrm{T}$ value of exon 9 and E545A at significance level of 0.05 was 1.89 and 1.83 (Table 4). Due to $\mathrm{T}$ value $>\mathrm{T}$ table, data were not significant (Kim, 2015). This significant result indicated that GC distribution in both amplicons was equal, as well as eliminated potentiality of

Table 4. Normality test of exon 9 and E545A sequence.

\begin{tabular}{lllll}
\hline Sample & Std. Deviation & Skewness & Kurtosis & t-test $(0.05)$ \\
\hline Exon 9 & 20.343 & 0.026 & -1.862 & $7.213>1.89$ \\
E545A & 23.422 & 0.368 & -1.267 & $7.187>1.83$ \\
\hline
\end{tabular}


(a)

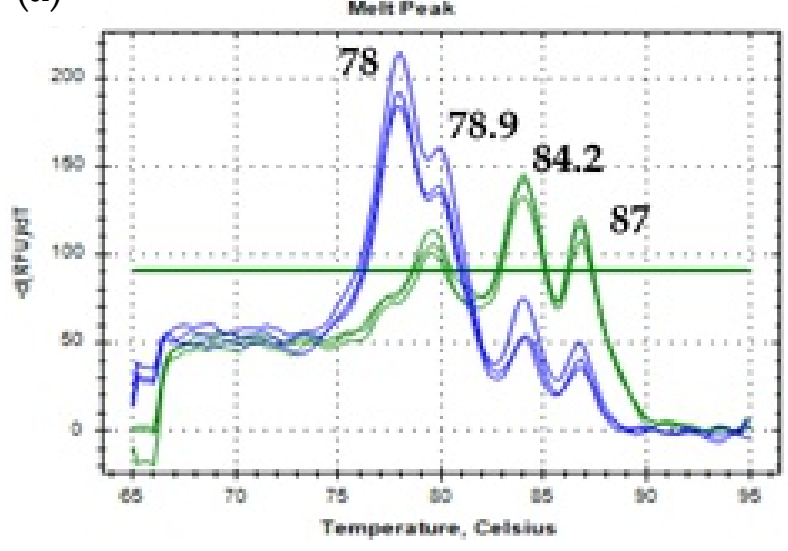

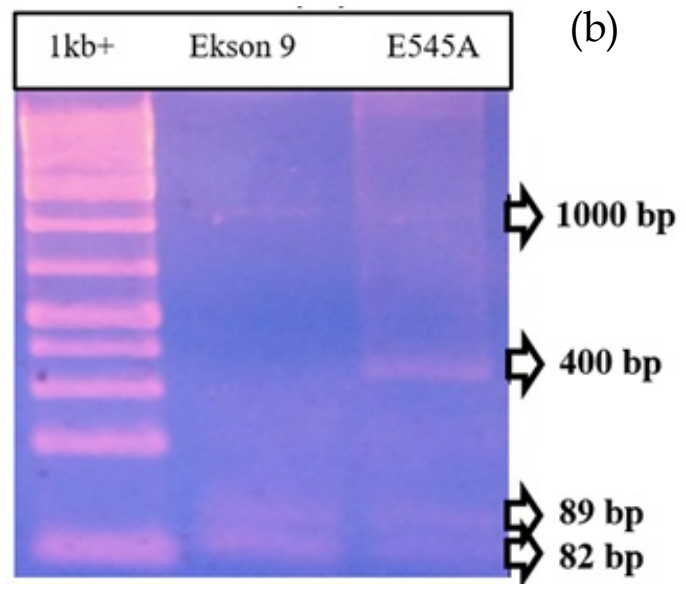

Figure 1. Optimization 1. (a) Melting peak of exon 9 (blue) and E545A (green) at annealing temperature of $62^{\circ} \mathrm{C}$; (b) visualization of qPCR result.

bimodal curve in further $\mathrm{pPCR}$ result (Abtahi et al., 2011).

\section{Optimization of Tm shift SYBR green I qPCR technique}

Optimization using condition 1 showed undesirable result as observed by the present of 4 peaks of two target samples. Tm of each peak was $78^{\circ} \mathrm{C}, 78.9^{\circ} \mathrm{C}, 84.2^{\circ} \mathrm{C}$, and $87^{\circ} \mathrm{C}$ (Figure 1a). Unspecific results indicated by presence of 4 bands at $1000 \mathrm{bp}, 400 \mathrm{bp}, 89 \mathrm{bp}$ and $82 \mathrm{bp}$ were found from optimization 1 (Figure 1b). The occurrence of this non-specific product suppressed formation of specific product, which could reduce efficiency of amplification reaction. Annealing temperature below optimum condition could be one of factors causing non-specific amplification (Kennedy and Oswald, 2011). In addition, Saunders and Lee (2013) reported that use of extension phase in PCR reaction with amplicon $<100 \mathrm{bp}$ could also lead to amplification of non-specific product.

In addition to non-specific amplification, domination of primer fw short to primer $f w$ long was observed as indicated in peak profile of exon 9 sample that was much higher than E545A This is due to activity existence of mismatch primer is lower than that of nonmismatch (Dorak, 2006). Increase in concentration of fw long was expected to enhance existence activity of non-mismatch primer.

The use of high annealing temperature and extension phase removal could eliminate amplification of non-specific product. Peak at $\mathrm{Tm}$ of $84.2^{\circ} \mathrm{C}$ and $87^{\circ} \mathrm{C} \mathrm{t}$ was not formed in optimization 2 . Two other peaks showed higher $\operatorname{Tm}\left(78.4^{\circ} \mathrm{C}\right.$ and $\left.80.4^{\circ} \mathrm{C}\right)$.

Presence of two peaks in optimization 2 resulted from activity of both forward. By comparing GC content and Tm, peak $78.4^{\circ} \mathrm{C}$ was representation of exon 9 while peak $80.4^{\circ} \mathrm{C}$ represented E545A. Marmur and Dorty (1962) reported that GC content positively correlated with $\mathrm{Tm}$. According to GC content of two amplicon sequences, GC content of exon 9 and E545A was 50\% and 56.2\%, respectively, meaning that $\mathrm{Tm}$ of E545A was higher than that of exon 9.

Presence of secondary peak (non-target) in exon 9 and E545A was negligible, primarily for annealing temperature of $64.3^{\circ} \mathrm{C}$ and $65^{\circ} \mathrm{C}$, because secondary peak was much lower than that of target peak (Figure 2a and c). Inversely, target peak at $63^{\circ} \mathrm{C}$ for E545A with $\mathrm{Tm}$ of $80.4^{\circ} \mathrm{C}$ was much lower than secondary peak with Tm of $78.4^{\circ} \mathrm{C}$ (Figure 2a). Annealing temperature of $65^{\circ} \mathrm{C}$ was selected since target peak of two samples was much higher in comparison with target peak at annealing temperature of $64.3^{\circ} \mathrm{C}$ (Figure 2c).

Furthermore, $\mathrm{Ct}$ (Cycle threshold) value of E545A, Exon 9 and NTC (Non Template Control) also showed differences. Ct reflects the cycle number at which amplification curve crosses the threshold. In the best condition (optimization 2 at annealing temperature of 65 $\left.{ }^{\circ} \mathrm{C}\right), \mathrm{Ct}$ was 10.07+0.1 (E545A), 13.005+0.007 (Exon 9) and 29,79 $\pm 1,28$ (NTC) (Figure 3a and 

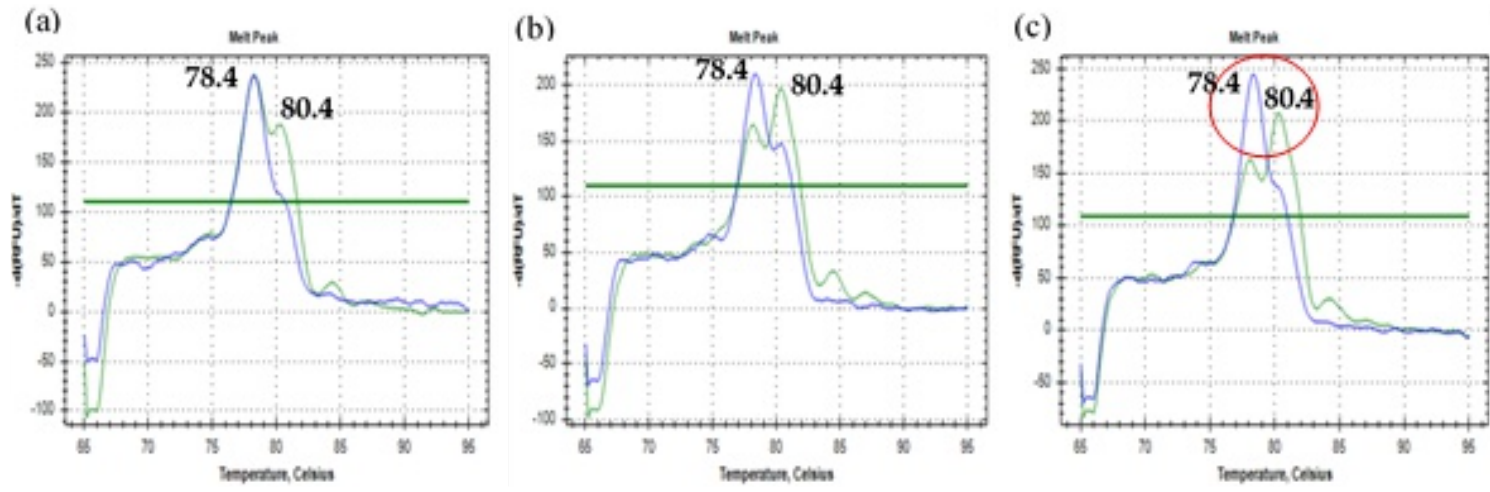

Figure 2. Optimization 2. qPCR result for exon 9 (blue) and E545A (green). (a) annealing temperature of $63^{\circ} \mathrm{C}$; (b) annealing temperature of $64.3^{\circ} \mathrm{C}$; and (c) annealing temperature of $65^{\circ} \mathrm{C}$.

b). In other optimization conditions, $\mathrm{Ct}$ of exon 9 and E545A was decreased as lower annealing temperature was used. In contrary, Ct of NTC seems increase as lower annealing temperature was used (Figure 3a-c). Presence of NTC was common, especially when nonspecific dye such as SYBR green I was used (Yang et al., 2007). Bustin et al., (2009) reported that NTC was negligible at distance of $\mathrm{Ct}$ sample was more than 5 because, in this distance, Ct of NTC and sample was distinguishable.

Using SYBR Green I, Ct could be affected by number of fluorescence unit of amplicon. Higher amplicon fluorescence unit was responsible for lower $\mathrm{Ct}$. Fluorescence unit was determined using model as previously prescribed by Colborn et al., (2008). The model assumed that each AT base pair generated 2 fluorescence units, meanwhile each GC base pair just generated 1 fluorescence unit. Using the model, fluorescence unit of both amplicons could be determined, that is, 123 for exon 9 $((2 \times 41 \mathrm{AT})+(1 \times 41 \mathrm{GC}))$ and 128 for $\mathrm{E} 545 \mathrm{~A}$ $((2 X 39 A T)+(1 \times 50 G C))$. These results were in accordance with qPCR result; the highest fluorescence unit (E545A) demonstrated lower $\mathrm{Ct}$. Higher fluorescence of amplicon led to faster movement of signal that crossed threshold (Thornton and Basu, 2011). Different Ct in both amplicons was useful to differentiate both target samples.

Reproducibility and repeatability of developing technique were determined by calculation of coefficient variance of intraassay for both samples. Tm was compared in each replication. Tm showed similar value in each replication: (a) $78.4^{\circ} \mathrm{C}$ (exon 9) and (b) $80.4^{\circ} \mathrm{C}$ (E545A) as presented in Table 5. This similarity resulted in the intra assay value of both samples was zero (0), indicating high reproducibility and repeatability of the developing method.

\section{Conclusions}

Method for detection of E545A PIK3CA gene was developed in a single tube. The best condition was obtained at optimization 2 with annealing temperature of $65^{\circ} \mathrm{C}$. At this condition, sample amplicon of exon 9 and
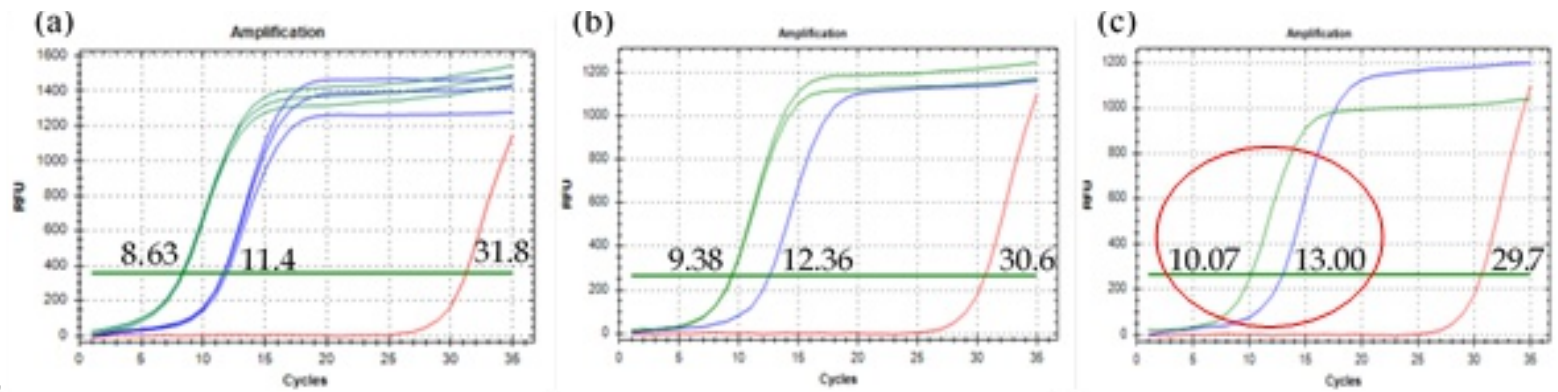

Figure 3. Amplification sample curve of exon 9 (blue), E545A (green) and NTC (red) in various annealing temperatures. (a) $62^{\circ} \mathrm{C}$; (b) $64.3^{\circ} \mathrm{C}$; and (c) $65^{\circ} \mathrm{C}$. 
E545A demonstrated various $\mathrm{Tm}$ and $\mathrm{Ct}$. Tm and $\mathrm{Ct}$ of exon 9 was $78.4^{\circ} \mathrm{C}$ and $13.005+0.007$, respectively, while Tm and $\mathrm{Ct}$ of E545A was $80.4^{\circ} \mathrm{C}$ and $\mathrm{Ct} 10.07+0.1$, respectively. Using these parameters, exon 9 and E545A samples could be distinguished.

\section{Acknowledgments}

This work was supported by these following grant from Laboratory of Medical Molecular Biology and Diagnostic, Research Center for Biotechnology - Indonesian Institute of Sciences Grant No. SP DIPA079.01.2.450083/2015.3403.002, PI. Dr. Eng. Desriani.

\section{References}

Al-Sukhun, S., Lataifeh, S. and Al-Sukhun, R. 2016. Defining the prognostic and predictive role of PIK3CA mutations: sifting through the conflicting data. Curr. Breast Cancer Rep., 8(2), 73-79

Bustin, S.A., Benes, V., Garson, J.A., Hellemans, J., Huggett, J., Kubista, M., Mueller, R., Nolan, T., Pfaffl, M.W. and Shipley, G.L., Vandesompele, J. And Wittwer, C.T. 2009. The MIQE guidelines: minimum information for publication of quantitative real-time PCR experiments. Clin. Chem., 55(4), 611-622.

Colborn, J.M., Byrd, B.D., Koita, O.A. and Krogstad, D.J. 2008. Estimation of copy number using SYBR Green: confounding by AT-rich DNA and by variation in amplicon length. Am. J. Trop. Med. Hyg., 79(6), 887-892.

Dorak, M.T.( 2006) Real-time PCR. New York: Taylor \& Francis Group.

Gashemi, A., Zahediasl, S. 2012. Normality test for statistical analysis: a guide for non-stasticians. Int. J. Endocrinol. Metab., 10(2), 486-489.

International Agency for Research on Cancer World Health Organization. 2012. GLOBOCAN 2012: Estimated cancer incidence, mortality and prevalance worldwide in 2012. [Internet]. [diunduh 1 Mei 2016]. Available on: globocan.iarc.fr/Pages/fact_sheets_ca ncer.aspx.
Kennedy, S. and Oswald, N. (2011) PCR troubleshooting and optimization: the essential guide. Norfolk: Caister Academic Press.

Kim, T.K. 2015. T test as a paramteric statistic. Korean J. Anesthesiol., 68(6), 540-546.

Margone, F.R., Bobrovnitchaia, I.G., Salaorni, S., Manuli, E. and Nagai, M.A. 2012. PIK3CA exon 20 mutatios are associated with poor progosis breast cancer patients. Clinics, 67(11), 12851290.

Marmur, J. and Dorty, P. 1962. Determination of the base composition of deoxyribonucleic acid from its thermal denaturation temprature. J. Mol. Biol., 5, 109-118.

Mihalcea, C.E., Morosanu, A.M., Murarasu, D., Puiu, L., Cinca, S., Voinea, S.C. and Mirancea, N. 2015. Particular molecular and ultrastructural aspacts in invasive mammary carcinoma. Romanian J. Morphol. Embryol., 56(4), 1371-1381.

Rexer, B.N., Chanthaphaychith, S., Dahlman, K.B. and Artega, C.L. 2014. Direct inhibition of PI3K in combination with dual HER2 inhibitors is required for optimal antitumor activity in HER2+ breast cancer cells. Breast Cancer Res., 16(1), R9.

Saunders, N.A. and Lee, M.A. (2013) Realtime PCR: advanced technologies and applications. Salisbury: Caister Academic Press.

Schultheiss, O.C. and Stanton, S.J. (2009). Assessment of salivary hormones. Harmon-Jones E, Beer JS, Eds. New York: Guilford Press.

Stare, S.M. and Jozefowicz, J.J. 2008. The effects of environmental factors on cancer prevalance rates and specific cancer mortality rates in a sample of OECD developed countries. Int. J. Appl. Econ., 5(2), 92-115.

Thornton, B. and Basu, C. 2010. Real-time PCR (qPCR) primer design using free online software. Biochemi. Mol. Biol. Educ., 39(2), 145-1154.

Wang, J., Chuang, K., Ahluwalia, M., Patel, S., Umblas, N., Mirel, D., Higuchi, R. 
and Germer, S. 2005. High-troughput SNP geotyping by single-tube PCR with Tm-shit primers. BioTechniques, 39, 885-893.

Widyastuti, P., Ariyanto, A., Triningsih, Susilo, V.Y. and Lestari, W. 2014. Validasi kit radioimmunoassay aflatoksin B1. Prosiding Seminar Nasional Sains dan Pendidikan Sains IX, 5(1), 518-522.

Yang, Z.Z., Habib, M., Shuai, J.B. and Fang, W.H. 2007. Detection of PCV2 DNA by SYBR Green I-based quantitative PCR. J. Zhejian. Univ. Sci. B., 8(3), 162-169. 